\title{
Sensitivity Optimization of Wafer Bonded Gravimetric CMUT Sensors
}

\author{
Mølgaard, Mathias J.G.; Hansen, J.M.F. ; Jakobsen, Mogens H.; Thomsen, Erik V.
}

Published in:

I E E E Journal of Microelectromechanical Systems

Link to article, DOI:

10.1109/JMEMS.2018.2868864

Publication date:

2018

Document Version

Peer reviewed version

Link back to DTU Orbit

Citation (APA):

Mølgaard, M. J. G., Hansen, J. M. F., Jakobsen, M. H., \& Thomsen, E. V. (2018). Sensitivity Optimization of Wafer Bonded Gravimetric CMUT Sensors. I E E E Journal of Microelectromechanical Systems, 27(6), 10891096. https://doi.org/10.1109/JMEMS.2018.2868864

\section{General rights}

Copyright and moral rights for the publications made accessible in the public portal are retained by the authors and/or other copyright owners and it is a condition of accessing publications that users recognise and abide by the legal requirements associated with these rights.

- Users may download and print one copy of any publication from the public portal for the purpose of private study or research.

- You may not further distribute the material or use it for any profit-making activity or commercial gain

- You may freely distribute the URL identifying the publication in the public portal 


\title{
Sensitivity Optimization of Wafer Bonded Gravimetric CMUT Sensors
}

\author{
Mathias J. G. Mølgaard ${ }^{\circledR}$, Jesper M. F. Hansen, Mogens H. Jakobsen, and Erik V. Thomsen
}

\begin{abstract}
Optimization of the mass sensitivity of wafer bonded resonant gravimetric capacitive micromachined ultrasonic transducers (CMUTs) is presented. Gas phase sensors based on resonant gravimetric CMUTs have previously been demonstrated. An important figure of merit of these sensors is the sensitivity which, for typical CMUT geometries, is increased by decreasing the radius of the CMUT cell. This paper investigates how to minimize the radius of CMUT cells fabricated using the wafer bonding process. The design and process parameters affecting the radius of the CMUT and hereby the sensitivity are studied through numerical simulations and atomic force microscopy measurements. An excellent fit was obtained between the simulations and measured profiles with a low relative error of $\leq 5 \%$, thus validating the simulation model. Two types of CMUTs are designed and fabricated using the design and process rules determined herein, with experimentally determined mass sensitivities of $0.46 \mathrm{~Hz} / \mathrm{ag}$ and $0.44 \mathrm{~Hz} / \mathrm{ag}$, respectively. The two CMUT devices have cavities made using the local oxidation of silicon (LOCOS) and reactive ion etching (RIE) process. For the LOCOS process, it was found that the smallest radius can be obtained by choosing a $\mathrm{Si}_{3} \mathrm{~N}_{4}$ oxidation mask and lowering the pad $\mathrm{SiO}_{2}$ thickness, vacuum gap height, and $\mathrm{Si}$ bump height. For the RIE process, the vertical dimensions do not influence the horizontal dimensions and consequently, equivalent rules do not exist.

[2018-0135]
\end{abstract}

Index Terms-CMUT, sensor, gravimetry, sensitivity, LOCOS.

\section{INTRODUCTION}

D ETECTION of chemical and biological analytes in the gas phase is important in several fields including homeland security, environmental monitoring, and in different branches of industry. Many different types of sensors exist but it has been demonstrated that Capacitive Micromachined Ultrasonic Transducers (CMUTs), used as resonant gravimetric mass sensors, can achieve a low Limit of Detection (LOD) [1] in the ag range [2] and a high mass sensitivity of up to $0.23 \mathrm{~Hz} / \mathrm{ag}$ [3]. These properties have e.g. been utilized to detect small concentrations of dimethyl methylphosphonate (DMMP) [2] and greenhouse gasses such as $\mathrm{CO}_{2}$ [4]. Furthermore, the flat and closed surface of the CMUT eases functionalization. Finally, the actuation and readout schemes are typically electrical which enables miniaturization of the sensor system. In conclusion, the CMUT

Manuscript received June 15, 2018; revised August 23, 2018; accepted September 1, 2018. Subject Editor R. Maboudian. (Corresponding author: Mathias J. G. Mølgaard.)

M. J. G. Mølgaard, M. H. Jakobsen, and E. V. Thomsen are with the Department of Micro and Nanotechnology, Technical University of Denmark, 2800 Kongens Lyngby, Denmark (e-mail: migmol@ nanotech.dtu.dk).

J. M. F. Hansen is with NIL Technology ApS, 2800 Kongens Lyngby, Denmark.

Color versions of one or more of the figures in this paper are available online at http://ieeexplore.ieee.org.

Digital Object Identifier 10.1109/JMEMS.2018.2868864 gravimetric sensor has a desirable combination of characteristics. Since the first CMUT was reported in 1994 [5] one of the main applications, for both researchers and companies, has been medical ultrasonic imaging [6]-[9]. Since then CMUTs have also been applied as e.g. biological or chemical sensors, typically based on the resonant gravimetric principle where a small change in the mass of the plate, due to absorbed analytes in the functionalization layer on the plate, results in a resonance frequency shift [4], [10], [11]. A higher mass sensitivity causes a higher resonance frequency shift for the same amount of added mass. The functionalization layer on the plate provides the sensor with a selectivity toward a desired analyte but typically also decreases the mass sensitivity of the sensor as it increases the mass of the oscillating parts.

In general, two fabrication methods have been used for fabricating CMUTs: a process based on sacrificial release and a process based on wafer bonding. The first CMUTs were fabricated using the sacrificial release process [5], that consists of depositing a sacrificial layer, which is selectively etched by an isotropic wet etch, after it has been covered by a plate layer, hereby forming the cavity of the device. In the wafer bonding process, first proposed by Huang et al. [12], cavities are defined in an insulating layer on a substrate wafer that is directly bonded to the plate.

In this paper the wafer bonding fabrication method is used where the cavities typically are defined by either one of two processes, namely the Reactive Ion Etch (RIE) process and Local Oxidation of Silicon (LOCOS) process [13]. In the RIE process cavities are dry etched in an insulating layer (typically $\mathrm{SiO}_{2}$ ), while in the LOCOS process two consecutive LOCOS steps result in cavities with a central silicon bump. A cross-sectional sketch of half a LOCOS and RIE defined cavity can be seen in Fig. 1, along with all relevant geometrical variables. The characteristic bird's beak structure is also shown in Fig. 1(a). The RIE and LOCOS processes differ on several points: the number of photolithography masks required is one less for the typical RIE process, thus decreasing the process cost and time. For the LOCOS device the vacuum gap height is decoupled from the post $\mathrm{SiO}_{2}$ height and small gaps can therefore be made while still maintaining a thick post $\mathrm{SiO}_{2}$, which decreases the parasitic capacitance between the top and bottom electrode. Hence, the electro-mechanical coupling coefficient is generally higher for the LOCOS device compared with a RIE device. Furthermore, the possibility of fabricating small vacuum gaps is beneficial since this causes lower pull-in voltages and the CMUT can hereby be operated at lower DC voltages. The pull-in voltage is the voltage at which the electrostatic 


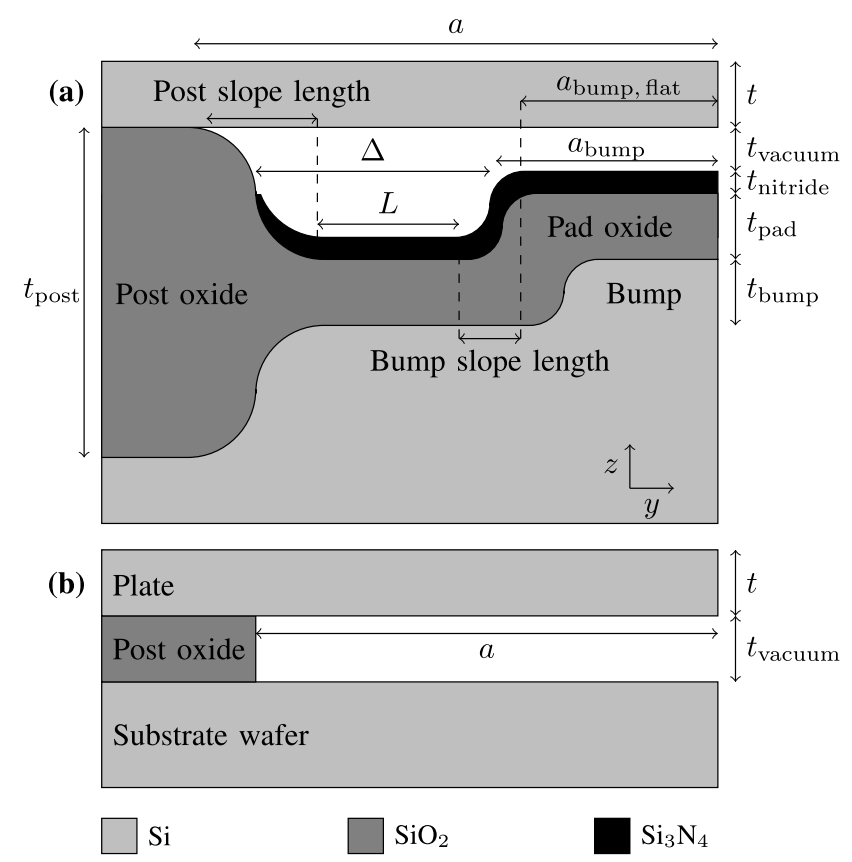

Fig. 1. Cross-sectional sketches of half (a) a LOCOS CMUT cell and (b) a RIE CMUT cell.

force, between the top and bottom electrodes, becomes larger than the restoring force from the stiffness of the plate and the plate collapses and touches the bottom of the cavity.

The limit of detection and mass sensitivity are the two most important figures of merit for any resonant gravimetric sensor, which in the ideal case should be as low and as high as possible, respectively. In this article the focus will be on maximizing the mass sensitivity of the CMUT sensor. The CMUT can be modeled as a 1-D linear harmonic oscillator and if the added mass on the plate is small compared with the mass of the plate itself, the sensitivity can be written as [10]:

$$
S=\frac{\partial f}{\partial m}=-\frac{1}{2} \frac{f_{\text {res }}}{m_{\text {plate }}} \propto \frac{1}{a^{4}},
$$

where $f_{\text {res }}$ is the resonance frequency, $m_{\text {plate }}$ is the mass of the plate and $a$ is the cell radius. For gravimetric gas sensors the sensitivity is often normalized by the plate surface area $A$ :

$$
S_{\text {norm }}=\frac{\partial f}{\partial m / A}=-\frac{1}{2} \frac{f_{\text {res }}}{m_{\text {plate }}} A \propto \frac{1}{a^{2}} .
$$

The variable dependencies in Eq. 1 and 2 are found by inserting the symbolic expressions for the resonance frequency and mass of a circular clamped plate. Hence, in order to increase the sensitivity the radius must be decreased. However, a practical lower limit of the radius exists, depending on the plate thickness, where the resonance peak signal approaches the noise floor and the resonance frequency becomes impractically high. Thus, the plates studied in this paper are assumed to have aspect ratios of $a / t \gtrsim 10$. For LOCOS cavities the smaller radii can become comparable with the lateral width of the bird's beak $\mathrm{SiO}_{2}$ which in Fig. 1(a) is defined as the 'slope length'. This ultimately limits the radius of the cavity and the sensitivity can hereby be limited by the process parameters
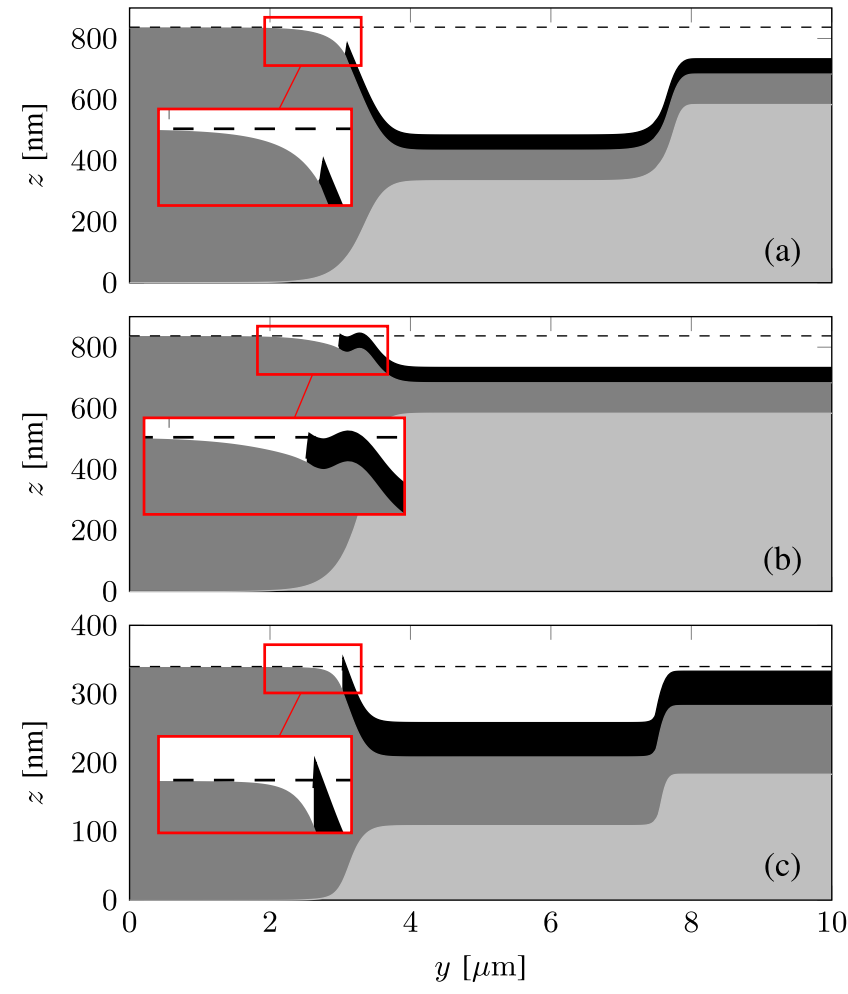

Fig. 2. Simulation results of three different CMUT designs. (a) This design does not inhibit wafer bonding. The designs in (b) and (c) both inhibit wafer bonding since the $\mathrm{Si}_{3} \mathrm{~N}_{4}$ layer protrudes above the post $\mathrm{SiO}_{2}$ at $y \approx 3 \mu \mathrm{m}$. In (b) the bump is placed too close to the post $\mathrm{SiO}_{2}$ and in (c) the post $\mathrm{SiO}_{2}$ is too low.

that affect the slope length of the bird's beak. The bird's beak structure have previously been studied extensively due to its use as an isolation structure in semiconductor manufacturing [14]-[16], since reduction of the horizontal size has been especially important due to the decrease in device dimensions. However, for small radii $(a<5 \mu \mathrm{m})$ CMUT cells the more complex geometry has yet to be investigated.

Not all CMUT designs can be fabricated. The main reason being the inability to bond the plate to the cavity wafer. For the RIE process it has previously been shown by Sarioglu et al. [17] how oxidation of convex silicon corners can lead to protrusions in the $\mathrm{SiO}_{2}$ at the corners which can hinder bonding. A study by Christiansen et al. [18] showed how the corners of a structured $\mathrm{SiO}_{2}$ layer are lifted when the wafer is re-oxidized in order to e.g. grow an insulation $\mathrm{SiO}_{2}$ layer, consequently making bonding impossible. Likewise, some LOCOS designs will hinder bonding but here the problem is slightly different as the solution depends on choosing the right combination of design and process parameters, where for the RIE process the problems are solved by adjusting the process flow. The main challenge, when designing the LOCOS device, from a fabrication point of view, is keeping the $\mathrm{Si}_{3} \mathrm{~N}_{4}$ layer from protruding above the post $\mathrm{SiO}_{2}$ at the cavity edge, thus inhibiting bonding. Fig. 2 shows three simulated LOCOS devices where (a) is an example of a device that can be fabricated, (b) cannot be fabricated due to the protruding $\mathrm{Si}_{3} \mathrm{~N}_{4}$ layer caused by an overlapping post $\mathrm{SiO}_{2}$ and silicon bump, either as a result of a bad design choice or misalignment in the lithography step. Finally, in situation (c) the post $\mathrm{SiO}_{2}$ is too 
(1)

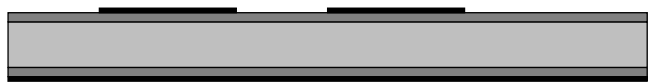

(2)

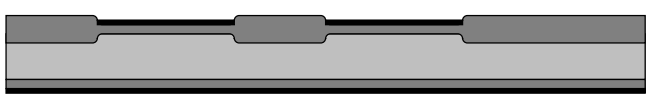

(3)

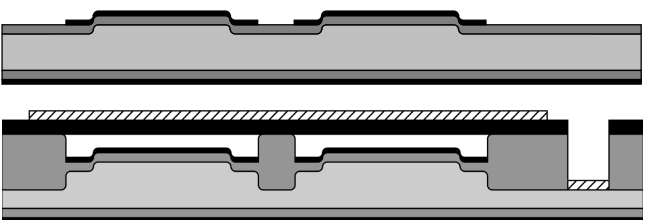

(a)
(1)

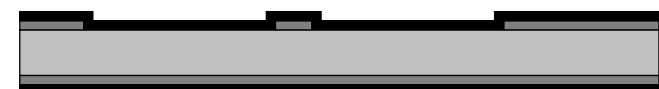

(2)

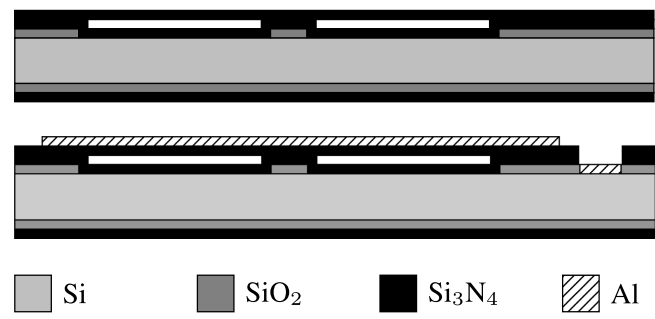

(b)

Fig. 3. Process flow of the (a) LOCOS and (b) RIE CMUT. In (a) step (1) a thermal pad $\mathrm{SiO}_{2}$ layer is grown and subsequently a LPCVD Si3 $\mathrm{N}_{4}$ layer is deposited and patterned by a RIE etch. In step (2) the LOCOS is performed, forming the Si bumps. Step (3) is a repeat of step (1). Finally, in step (4) the second LOCOS is performed and the cavities are seal under vacuum by fusion bonding a $\mathrm{Si}_{3} \mathrm{~N}_{4}$ layer to the cavity wafer. Openings to the bottom electrode are made and $\mathrm{Al}$ is deposited and wet etched. In (b) step (1) a thermal $\mathrm{SiO}_{2}$ is grown and patterned by a RIE etch. Next a LPCVD $\mathrm{Si}_{3} \mathrm{~N}_{4}$ layer is deposited and the subsequent steps are the same as in the LOCOS process.

TABLE I

Table of Target and Measured Values for the Seven Wafers Fabricated FOR THE EXPERIMENTAL VALIDATION OF THE SiMULATION MODEL

\begin{tabular}{lcccccccc}
\hline Parameter & \multicolumn{7}{c}{ Wafer number } & \\
\cline { 2 - 8 } & 1 & 2 & 3 & 4 & 5 & 6 & 7 & Unit \\
\hline$t_{\text {pad }}$ target & 0 & 10 & 50 & 100 & - & - & - & {$[\mathrm{nm}]$} \\
$t_{\text {pad measured }}$ & 0 & 10.6 & 56 & 99.4 & - & - & - & {$[\mathrm{nm}]$} \\
${\text { Mask } \mathrm{SiO}_{2} \text { thickness target }}_{\text {Mask } \mathrm{SiO}_{2} \text { thickness measured }}$ & - & - & - & - & 1000 & 2000 & 3000 & {$[\mathrm{~nm}]$} \\
$t_{\text {bump target }}$ & 250 & - & - & - & 963 & 1964 & 2950 & {$[\mathrm{~nm}]$} \\
$t_{\text {bump measured }}$ & 244 & 241 & 250 & 250 & 250 & 250 & 250 & {$[\mathrm{~nm}]$} \\
Relative difference between & 2.4 & 3.6 & 3.6 & 3.6 & 6.4 & 1.2 & 4 & {$[\%]$} \\
target and measured $t_{\text {bump }}$ & & & & & & & & \\
\hline
\end{tabular}

low, which e.g. could happen if a very small gap is wanted. The simulation model is discussed and validated later. The failure modes in Fig. 2(b) and (c) can be solved by removing the $\mathrm{Si}_{3} \mathrm{~N}_{4}$ layer in the cavity while protecting the post $\mathrm{SiO}_{2}$ with an etch mask. This can be done at the expense of additional processing steps and an extra lithography step [19]. However, since minimizing the number of process steps and lithography masks is desirable, this paper investigates LOCOS devices fabricated without removal of the $\mathrm{Si}_{3} \mathrm{~N}_{4}$ layer.

In this paper the design of high mass sensitivity wafer bonded CMUTs is studied by means of AFM and numerical simulations. In addition, LOCOS and RIE CMUTs are fabricated and the feasibility of using a $\mathrm{Si}_{3} \mathrm{~N}_{4}$ mask for both LOCOS steps is demonstrated. Furthermore, it is studied how the choice of oxidation masking material and process parameters influences the LOCOS device and hereby ultimately the minimum radius one can achieve and thus the maximum mass sensitivity. Finally, the experimental sensitivities of the fabricated LOCOS and RIE devices are compared with the theoretical values.

\section{Methods}

Standard cleanroom fabrication techniques were used to fabricate LOCOS profiles for experimental verification of the numerical simulation model, as well as LOCOS and RIE CMUT devices.

\section{A. Simulation Model}

A numerical simulation model was made using the process simulator ATHENA (Silvaco, Inc., California) where part of the LOCOS process in Fig. 3(a) was simulated. The mesh was optimized so the smallest mesh sizes were centered around the position where the bird's beak is formed. The size of the mesh in the $\mathrm{SiO}_{2}$ has a maximum vertical length of $5 \mathrm{~nm}$ and a maximum horizontal length of $25 \mathrm{~nm}$. These mesh sizes are chosen based on a mesh convergence study.

In the following the fabricated LOCOS structures used to verify the simulation model are described. Specifically, square silicon bumps were fabricated using the LOCOS process following steps (1)-(2) in Fig. 3(a), using both $\mathrm{SiO}_{2}$ and $\mathrm{Si}_{3} \mathrm{~N}_{4}$ as oxidation mask material. Table I shows an overview of the seven wafers oxidized in the experiment. The pad $\mathrm{SiO}_{2}$ thickness and thickness of the $\mathrm{SiO}_{2}$ mask layer were varied resulting in Si bumps of approximately the same height but with differing profiles. The wafers used were (100) oriented single side polished 4" Si wafers with an electrical resistivity of $1-10 \Omega \mathrm{cm}$. All thermal oxidations for the bump fabrication and simulation were performed in a wet atmosphere at a temperature of $1100^{\circ} \mathrm{C}$. Stoichiometric $\mathrm{Si}_{3} \mathrm{~N}_{4}$ was deposited using a Low Pressure Vapor Deposition (LPCVD), resulting in a $50 \mathrm{~nm}$ thick layer on all the wafers with $\mathrm{Si}_{3} \mathrm{~N}_{4}$ masks. Finally, all wafers underwent a LOCOS step with different 


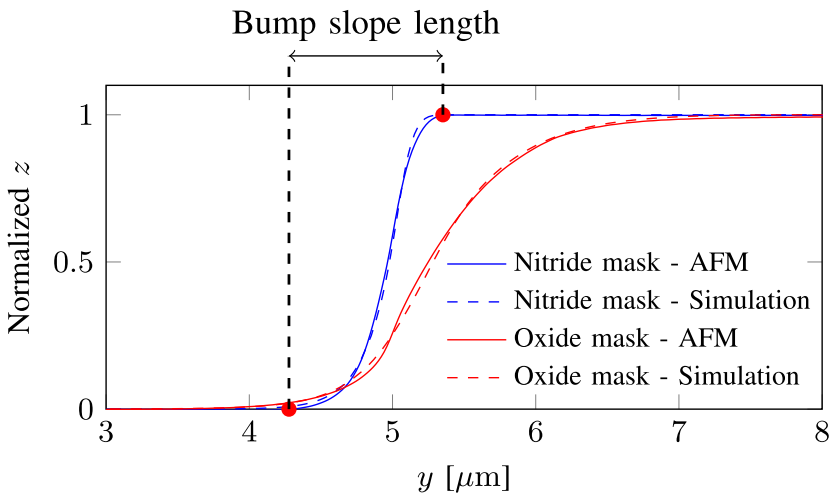

Fig. 4. Silicon bump profiles made using either an $\mathrm{SiO}_{2}$ mask (thickness: $1 \mu \mathrm{m})$ or a $\mathrm{Si}_{3} \mathrm{~N}_{4}$ mask with a pad $\mathrm{SiO}_{2}$ thickness of $t_{\mathrm{pad}}=10 \mathrm{~nm}$. AFM measurements and simulation results are shown together. The distance between the two points, located at the positions where the slope is $<1 \%$, is denoted the slope length.

oxidation durations, in order to reach a bump height of $250 \mathrm{~nm}$. Subsequently, all layers were stripped from the wafer, leaving only the $\mathrm{Si}$ surface and the bare silicon bumps were characterized by AFM (Dimension Icon, Bruker). The maximum relative difference between the target and measured Si bump height was found to be $6.4 \%$, which is low enough to allow for a comparison of the profiles.

Fig. 4 shows an example of an experimental and simulated Si bump profile, for bumps fabricated using $\mathrm{Si}_{3} \mathrm{~N}_{4}$ masks and $\mathrm{SiO}_{2}$ masks. The measured and simulated profiles have been translated relative to each other along the $y$-axis to the position of minimum relative error. The relative errors between the measured and simulated profiles were found to be $\leq 5 \%$. This consistently low error for both the $\mathrm{Si}_{3} \mathrm{~N}_{4}$ and $\mathrm{SiO}_{2}$ masks demonstrates the validity of the simulation model. Fig. 4 also shows an example of the slope length, shown in Fig. 1, of one of the profiles. The slope length is defined as the horizontal distance between the two points were the slope first becomes $<1 \%$, that is: where the profile becomes flat. The 2D AFM profiles are calculated by taking the mean of the scan lines in the direction orthogonal to the y-plane. The AFM scans consist of 512 scan lines parallel to the $y$-axis and each scan line is made up of 512 data points. The scan area is a $10 \mu \mathrm{m} \times 10 \mu \mathrm{m}$ square and no artifacts were observed due to the relatively slowly varying slope of the profiles. The tilt of the scan is removed by fitting and subtracting a first order polynomial plane from the scan.

\section{B. CMUT Fabrication Processes}

In this section the fabrication processes for the LOCOS device (Fig. 3(a)) and RIE device (Fig. 3(b)) are presented. In the original LOCOS process by Park et al. [13] the first oxidation mask was a thermally grown $\mathrm{SiO}_{2}$ layer, while in this process it is a $\mathrm{Si}_{3} \mathrm{~N}_{4}$ layer. The choice of masking material becomes increasingly important as the dimensions of the CMUTs decrease as will be explained in more detail later. We used a $\mathrm{Si}_{3} \mathrm{~N}_{4}$ layer as the plate, thus eliminating the need for a Silicon On Insulator (SOI) wafer, that are both more expensive and not easily attainable for thin $(<200 \mathrm{~nm})$ device layers for 4 " wafers. The silicon substrate wafers have a low electrical resistivity ( $<0.025 \Omega \mathrm{cm},(100))$ in order to decrease the electrical resistance in the bottom electrode.

In the LOCOS process in Fig. 3(a) step (1) a $10 \mathrm{~nm}$ thermal pad $\mathrm{SiO}_{2}$ layer is grown by dry oxidation at $900{ }^{\circ} \mathrm{C}$ and $50 \mathrm{~nm}$ $\mathrm{Si}_{3} \mathrm{~N}_{4}$ is deposited by LPCVD. The pad $\mathrm{SiO}_{2}$ acts as a buffer layer between the tensile stressed $\mathrm{Si}_{3} \mathrm{~N}_{4}$ layer and the silicon surface. Subsequently, the $\mathrm{Si}_{3} \mathrm{~N}_{4}$ layer is patterned by RIE dry etching using an UV photoresist mask. In step (2) the first LOCOS is performed by wet oxidation at $1100^{\circ} \mathrm{C}$ to form the $\mathrm{Si}$ bumps and afterwards all layers but the silicon are stripped by a buffered $\mathrm{HF}$ (BHF) etch and a $160^{\circ} \mathrm{C}_{3} \mathrm{HO}_{4}$ etch. Another pad $\mathrm{SiO}_{2}$ is grown (dry, $900^{\circ} \mathrm{C}$ ) in step (3) and $\mathrm{Si}_{3} \mathrm{~N}_{4}$ is deposited using LPCVD and wet etched $\left(160^{\circ} \mathrm{C}, \mathrm{H}_{3} \mathrm{PO}_{4}\right)$ using a poly-silicon etching mask. The second LOCOS (wet, $1100{ }^{\circ} \mathrm{C}$ ) is performed in step (4) hereby forming the cavities. The substrate wafer is bonded, under vacuum, to a silicon wafer with a $137 \mathrm{~nm} \mathrm{Si}_{3} \mathrm{~N}_{4}$ layer constituting the plate. The bonded wafer stack is annealed at $1150^{\circ} \mathrm{C}$ and the silicon handle wafer is selectively etched by $\mathrm{KOH}(28 \mathrm{wt} \%$, $80^{\circ} \mathrm{C}$ ) using the $\mathrm{Si}_{3} \mathrm{~N}_{4}$ plate layer as an etch stop layer. Furthermore, openings to the bottom electrode are dry etched and $100 \mathrm{~nm} \mathrm{Al}$ is deposited by e-beam deposition and subsequently etched in a solution of $\mathrm{H}_{2} \mathrm{O}: \mathrm{H}_{3} \mathrm{PO}_{4}$ (1:2) at room temperature.

In the RIE process in Fig. 3(b) step (1) a thermal $225 \mathrm{~nm} \mathrm{SiO}{ }_{2}$ layer is grown (wet, $1050{ }^{\circ} \mathrm{C}$ ) and patterned by dry etching, forming cavities. A $27 \mathrm{~nm} \mathrm{Si} \mathrm{S}_{4}$ layer is deposited using LPCVD, thus covering both sides of the wafer. In step (2) the cavity wafer is bonded to a silicon wafer with a $50 \mathrm{~nm} \mathrm{Si}_{3} \mathrm{~N}_{4}$ layer. All subsequent process steps are identical to the steps described for the LOCOS process, except that the Al layer thickness in this case was $50 \mathrm{~nm}$.

The structures are characterized in Section III-B where the dimensions are measured using Scanning Electron Microscopy (SEM) and the mass sensitivity is determined using impedance spectroscopy.

\section{RESULTS AND DISCUSSION}

The mass sensitivity was in Eq. 1 shown to be dependent on the radius of the CMUT cell, where smaller radii result in higher sensitivities.

The sensitivity of a RIE CMUT is trivial to calculate as the lateral dimensions are not coupled to the vertical dimensions due to the dry etched cavities. That is, no matter the post $\mathrm{SiO}_{2}$ height the radius will stay the same and consequently so will the sensitivity. The minimum RIE cavity radius is therefore only limited by the minimum feature size of the lithography process.

For the LOCOS device the bird's beak profile results in a coupling between the vertical and lateral dimensions which ultimately limits the radius and hereby the sensitivity. In the following section the parameters influencing the LOCOS profile and thus sensitivity are investigated through AFM measurements and simulations. Furthermore, the limited design space is investigated due to the fabrication limitations exemplified in Fig. 2. Finally, the fabricated CMUT devices are experimentally characterized. 


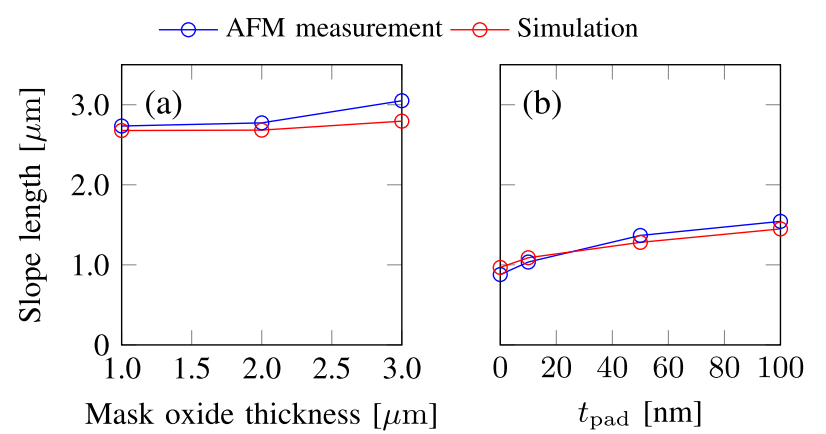

Fig. 5. (a) Slope length as a function of the $\mathrm{SiO}_{2}$ oxidation mask thickness. (b) Slope length as a function of the pad $\mathrm{SiO}_{2}$ thickness, under the $\mathrm{Si}_{3} \mathrm{~N}_{4}$ oxidation mask. The simulations and measurements agree with a maximum relative difference of $10 \%$

\section{A. LOCOS Cavity Optimization}

To minimize the radius of the LOCOS CMUT cell and the Si bump radius, the slope length (Fig. 1 and 4 ) should be minimized. Fig. 5 shows that the slope length is approximately 3 times shorter for thin pad oxides $\left(t_{\mathrm{pad}}=0 \mathrm{~nm}\right.$ to $\left.10 \mathrm{~nm}\right)$ as compared with a $\mathrm{SiO}_{2}$ mask to 2 times shorter for thicker pad oxides $\left(t_{\mathrm{pad}}=100 \mathrm{~nm}\right)$. In addition, Fig. 5(a) shows that the slope length is roughly constant as a function of the thickness of the $\mathrm{SiO}_{2}$ mask. Whereas, Fig. 5(b) demonstrates an increasing slope length for a thicker pad $\mathrm{SiO}_{2}$, since the diffusivity of the oxidizing species $\left(\mathrm{O}_{2}\right.$ or $\left.\mathrm{H}_{2} \mathrm{O}\right)$ is higher in $\mathrm{SiO}_{2}$ than $\mathrm{Si}_{3} \mathrm{~N}_{4}$ and a thicker pad $\mathrm{SiO}_{2}$ layer allows for a higher lateral influx of $\mathrm{H}_{2} \mathrm{O}$ under the mask. Likewise, increased lateral diffusion is the cause for the longer slope lengths when $\mathrm{SiO}_{2}$ is used as the masking material compared with a $\mathrm{Si}_{3} \mathrm{~N}_{4}$ mask. This agrees well with what is found in the literature [14]-[16]. The measured and simulated slope lengths are in agreement with each other, showing a maximum relative error of $\leq 10 \%$ and demonstrating the same scaling tendencies.

When the radius of the CMUT cell decreases, the radius of the silicon bump must decrease as well and consequently the slope length of the bump will make up an increasing fraction of the total bump radius. As a result, the expected capacitance of the cell is decreased, the expected pull-in voltage is increased and wafer bonding can be rendered impossible if the slope of the bump overlaps too much with the cavity edge, as was the case in Fig. 2(b). Thus, it is important to control the bump slope length and take it into consideration when designing the CMUT. In most cases it is desirable to minimize the slope length, hereby creating the most square-like corners for the bump. Fig. 6 shows the ratio of the flat part of the bump to the bump radius as a function of the bump radius for different oxidation masking materials and bump heights. As the bump radius increases the ratio approaches $100 \%$. The $\mathrm{Si}_{3} \mathrm{~N}_{4}$ mask results in more well defined bumps with square-like corners where a larger fraction of the bump reaches the designed height. Furthermore, higher bumps lead to lower ratios and this difference is relatively larger for the $\mathrm{SiO}_{2}$ mask. All in all this favors using a $\mathrm{Si}_{3} \mathrm{~N}_{4}$ mask.

When designing bumps with radii in the sub $\sim 5 \mu \mathrm{m}$ range it can therefore be advantageous to use $\mathrm{Si}_{3} \mathrm{~N}_{4}$ as the masking

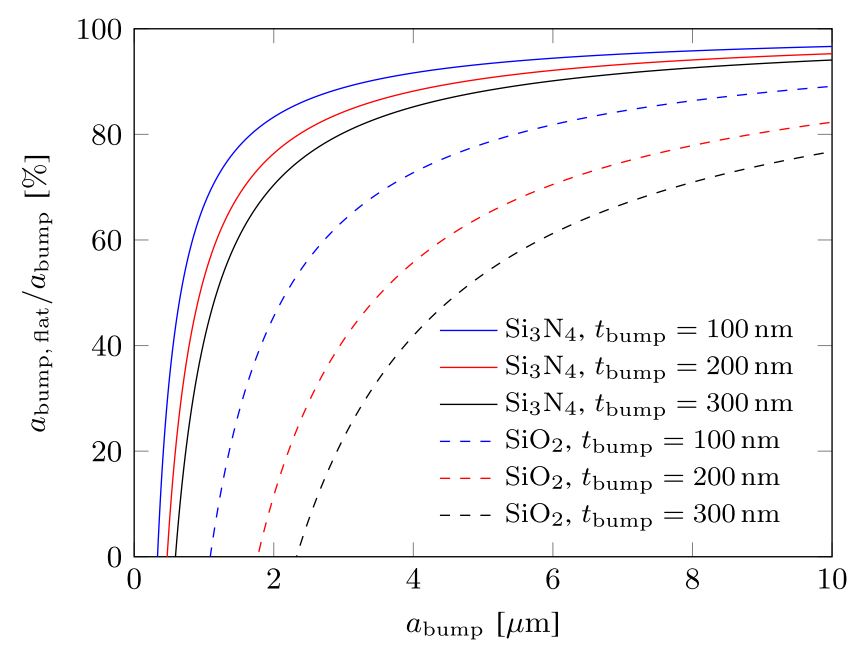

Fig. 6. Simulation results: $a_{\text {bump, flat }}$ (see Fig. 1) normalized to $a_{\text {bump }}$ as a function of $a_{\text {bump for }} \mathrm{Si}_{3} \mathrm{~N}_{4}\left(t_{\mathrm{pad}}=10 \mathrm{~nm}\right)$ and $\mathrm{SiO}_{2}$ (mask height: $2 \mu \mathrm{m}$ ) as masking material at three bump heights.

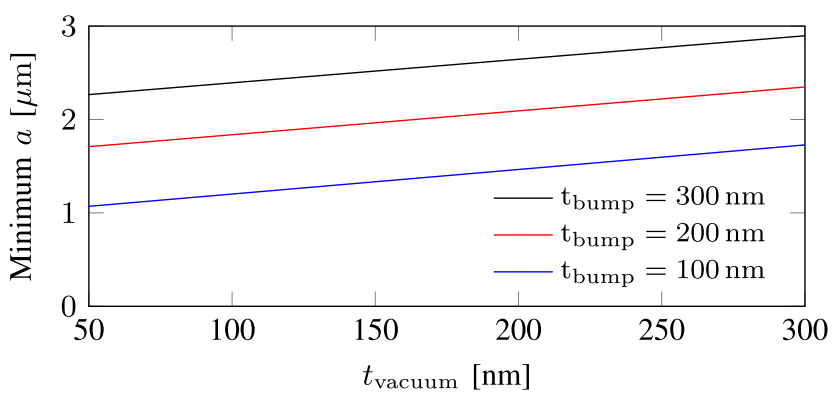

Fig. 7. Minimum cell radius as a function of the vacuum gap height for three bump heights, when $L=0 \mathrm{~nm}$ and $a_{\text {bump, flat }}=0 \mathrm{~nm}$.

material. In the article by Park et al. [13] the masking material for the first LOCOS process was $\mathrm{SiO}_{2}$ but it was noted that $\mathrm{Si}_{3} \mathrm{~N}_{4}$ could have been used at the cost of additional process steps. Therefore, the choice of LOCOS masking material is a trade-off between tight dimension control and reducing the number of process steps.

What is the minimum radius and hence sensitivity one can achieve with a LOCOS CMUT cell? In order to answer this question two limitations are imposed on the structures: the bump and the post $\mathrm{SiO}_{2}$ should not overlap, that is $L \geq 0 \mathrm{~nm}$ (see Fig. 1) and the bump should at least reach the designed height in the center, that is $a_{\text {bump,flat }} \geq 0 \mathrm{~nm}$. The minimum radius is obtained when both of these variables are zero. Fig. 7 shows a plot of the minimum radius as a function of the vacuum gap height for three bump heights. As the vacuum gap height is increased the minimum radius increases since the post $\mathrm{SiO}_{2}$ height increases, thus making the slope length of the post $\mathrm{SiO}_{2}$ longer. The same effect is seen when the bump height is increased, resulting in larger minimum cavity radii. Eq. 1 shows that these minimum radii given by Fig. 7 for the LOCOS structure, directly determines the maximum sensitivity.

In order to map out the design space for LOCOS cavities, simulations were made where the post $\mathrm{SiO}_{2}$ height and bump height have been varied. Fig. 8 shows a plot where the contour 


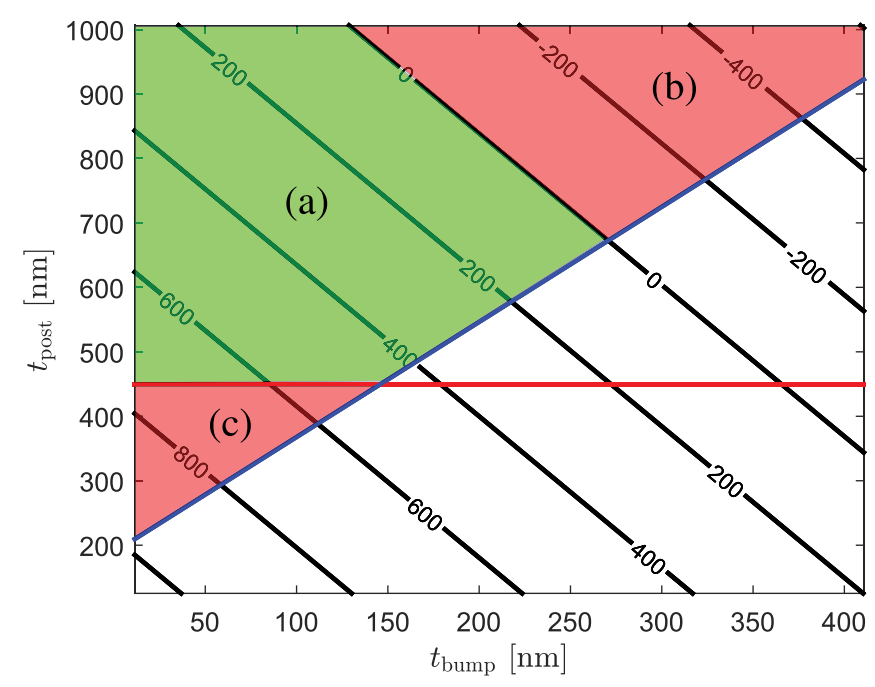

Fig. 8. Contour plot showing the length of the flat region between the cavity and bump $L$ (see Fig. 1) as a function of the $\mathrm{SiO}_{2}$ post thickness

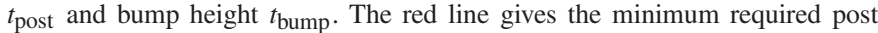
$\mathrm{SiO}_{2}$ height for successful bonding and the blue line are the points at which the vacuum gap height is $0 \mathrm{~nm}$. The distance between the cavity and bump: $\Delta=1.5 \mu \mathrm{m}$, bump and cavity $\mathrm{Si}_{3} \mathrm{~N}_{4}$ thickness $t_{\text {nitride }}=50 \mathrm{~nm}$ and bump and cavity pad $\mathrm{SiO}_{2}$ thicknesses of $t_{\mathrm{pad}}$, bump $=10 \mathrm{~nm}$ and $t_{\text {pad, cavity }}=100 \mathrm{~nm}$, respectively.

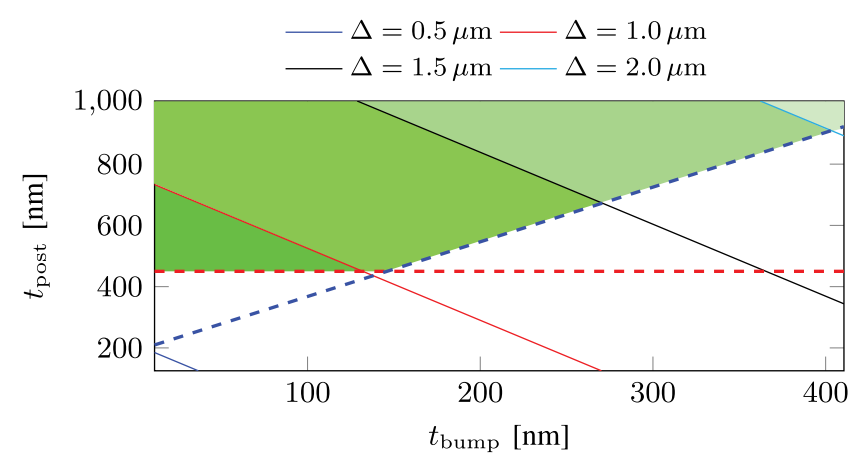

Fig. 9. The solid lines show where $L=0 \mathrm{~nm}$ and are plotted for different values of $\Delta$ as a function of $t_{\text {bump }}$ and $t_{\text {post }}$. The red dashed line gives the minimum required post $\mathrm{SiO}_{2}$ height for successful bonding and the blue dashed line are the points at which the vacuum gap height is $0 \mathrm{~nm}$. $\mathrm{Si}_{3} \mathrm{~N}_{4}$ thickness $t_{\text {nitride }}=50 \mathrm{~nm}$ and bump and cavity pad $\mathrm{SiO}_{2}$ thicknesses of $t_{\text {pad, bump }}=10 \mathrm{~nm}$ and $t_{\text {pad, cavity }}=100 \mathrm{~nm}$, respectively.

lines are the flat distance, $L$ (see Fig. 1), between the bump and the post $\mathrm{SiO}_{2}$ as a function of $t_{\text {post }}$ and $t_{\text {bump. }}$. The plot is valid for a specific set of parameters, given in the figure caption, but the overall shape of the plot is general for all LOCOS designs. The parameter $\Delta$ is the designed distance on the photolithographic mask between the bump and cavity edge and in this plot it is $\Delta=1.5 \mu \mathrm{m}$. The three colored regions (a), (b) and (c) correspond to the three situations in Fig. 2. Region (a) is limited by the red line that denotes the minimum post $\mathrm{SiO}_{2}$ height, the blue line at which the vacuum gap is zero and the $L=0$-contour line which is the limit where the bump and post $\mathrm{SiO}_{2}$ start to overlap. Thus, staying inside the green region (a) ensures a LOCOS design that can be successfully fabricated.

Fig. 9 shows that as the bump to cavity edge distance, $\Delta$ increases, so does the design space, here shown as green areas.
The solid lines are where $L=0 \mathrm{~nm}$, here plotted for several values of $\Delta$. The smallest $\Delta \mathrm{s}$ are typically found for small radii cells which are here seen to be the most limited in their design space. Therefore, these design rules are especially important for these smaller radius CMUT cells, which are typical for CMUTs used for sensing, when a high mass sensitivity is wanted.

In conclusion, all variables that affect the LOCOS profile will ultimately affect the sensitivity, capacitance and pull-in voltage. Hence, being able to predict the effect on the final fabricated structure is important. The shortest slope length for the $\mathrm{Si}$ bump and post $\mathrm{SiO}_{2}$ and hereby the smallest cell radii is obtained by using a $\mathrm{Si}_{3} \mathrm{~N}_{4}$ mask with a thin pad $\mathrm{SiO}_{2}$ $\left(t_{\text {pad }}\right)$ and choosing a low Si bump height and a small vacuum gap, since this yields the lowest post $\mathrm{SiO}_{2}$ height. The pad $\mathrm{SiO}_{2}$ thickness for the first LOCOS step can be made thin as these layers are subsequently stripped. However, the pad $\mathrm{SiO}_{2}$ thickness for the second LOCOS step is sometimes determined by the requirement for the CMUT cell to prevent electrical breakdown if pull-in occurs. Finally, the design space of LOCOS cavities were investigated and it was shown that for high sensitivity, small radii cavities the design space is limited.

\section{B. CMUT Sensors}

Two CMUT devices have been fabricated: a LOCOS and a RIE device, following the process flows in Fig. 3. The design of the LOCOS CMUT utilized the findings above to minimize the slope lengths of the bump and post $\mathrm{SiO}_{2}$. Namely, using $\mathrm{Si}_{3} \mathrm{~N}_{4}$ as masking material in both LOCOS steps and having a pad $\mathrm{SiO}_{2}$ thickness of only $10 \mathrm{~nm}$. Furthermore, the vacuum gap is just $65 \mathrm{~nm}$, resulting in a relatively low post $\mathrm{SiO}_{2}$ height, hereby shortening the post $\mathrm{SiO}_{2}$ slope length further. The RIE device has an insulation $\mathrm{Si}_{3} \mathrm{~N}_{4}$ layer which both increases the breakdown voltage when in pull-in and prevents potential leakage currents from running during operation. The choice of a $\mathrm{Si}_{3} \mathrm{~N}_{4}$ plate for this device results in a wafer bonding interface between two $\mathrm{Si}_{3} \mathrm{~N}_{4}$ surfaces; two materials that empirically are more difficult to bond than e.g. $\mathrm{Si}_{-} \mathrm{SiO}_{2}$ or $\mathrm{Si}_{3} \mathrm{~N}_{4}-\mathrm{SiO}_{2}$. The bonding strength is increased between the two $\mathrm{Si}_{3} \mathrm{~N}_{4}$ surfaces by oxidizing the $\mathrm{Si}_{3} \mathrm{~N}_{4}$ surfaces at a high temperature in a wet atmosphere, hereby creating a thin layer of oxy- $\mathrm{Si}_{3} \mathrm{~N}_{4}$ [20].

Two SEM cross-sections of the devices can be seen in Fig. 10. Fig. 10(a) shows a RIE cell with a well-defined vertical post $\mathrm{SiO}_{2}$ cavity edge. Fig. 10(b) shows the LOCOS cell with the central Si bump and (c) is a zoom in on the bird's beak profile at the cavity edge. The $\mathrm{Si}_{3} \mathrm{~N}_{4}$ layer is seen to end well below the bonding surface. The cracked surface is the result of a sputtered Au layer which was applied in order to prevent charge build up during imaging. The dimensions of the two cells are shown in Table II, where the thickness of the Au layer has been subtracted from the measured plate thickness. The Si bump is misaligned relative to the cavity and is therefore not placed completely centered in the cavity which highlights one of the challenges of making the cavities smaller, namely the increasing alignment tolerances. Indeed, if the Si bump is misaligned so much that it overlaps with the post $\mathrm{SiO}_{2}$, bonding can be hindered which is exemplified 

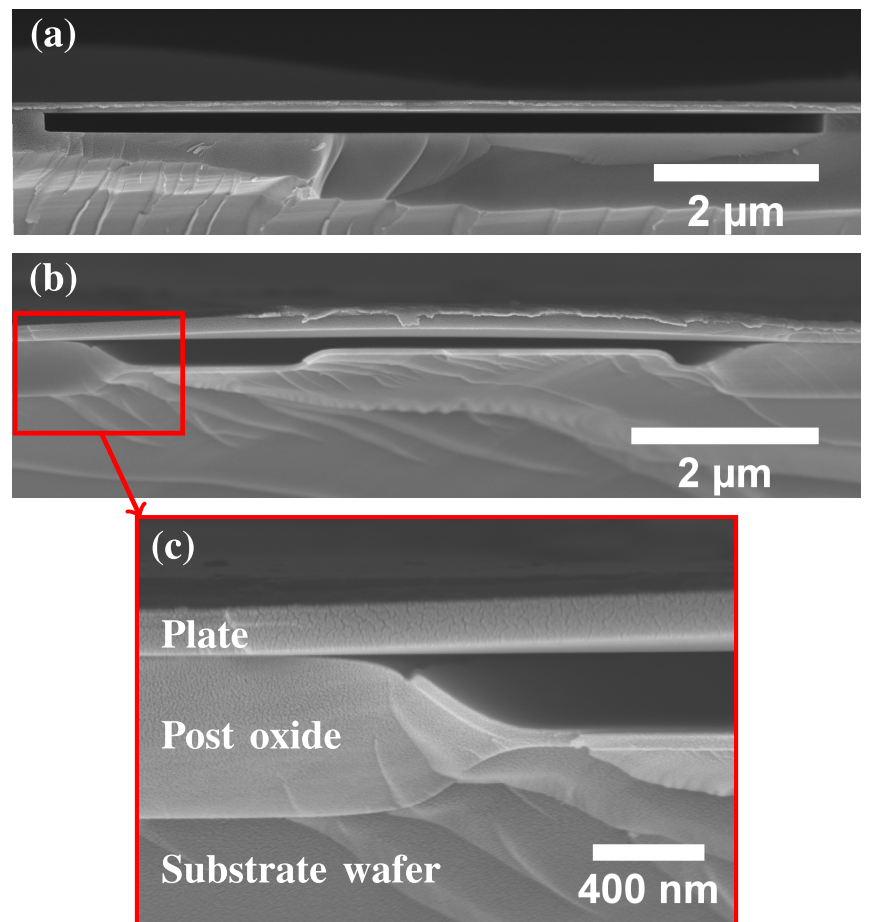

Fig. 10. Scanning electron microscope images of cross-sections of a single CMUT cell for (a) the RIE device, (b) the LOCOS device and (c) zoom in at the bird's beak.

TABLE II

MeAsured Dimensions AND PRoperties OF THE LOCOS AND RIE DEVICES

\begin{tabular}{lccc}
\hline Dimension & Unit & LOCOS & RIE \\
\hline Plate thickness & {$[\mathrm{nm}]$} & 137 & 51 \\
Vacuum gap height & {$[\mathrm{nm}]$} & 65 & 235 \\
Post $\mathrm{SiO}_{2}$ thickness & {$[\mathrm{nm}]$} & 582 & 235 \\
Bump height & {$[\mathrm{nm}]$} & 180 & - \\
Pad $\mathrm{SiO}_{2}$ & {$[\mathrm{~nm}]$} & 10 & - \\
Cavity $\mathrm{Si}_{3} \mathrm{~N}_{4}$ & {$[\mathrm{~nm}]$} & 50 & 27 \\
Plate radius & {$[\mu \mathrm{m}]$} & 3.75 & 5.0 \\
Pull-in voltage & {$[\mathrm{V}]$} & 45 & 91 \\
\hline
\end{tabular}

in Fig. 2(b). Comparing the LOCOS and RIE device it is evident how the sloped part of the LOCOS device makes up a significant part of the total cavity area while the RIE device in unaffected by this.

The sensitivity of the devices can be calculated using Eq. 1 but the sensitivity can also be measured directly by measuring the resonance frequency shift when a known mass is added to the plate. In order for the CMUT to stay in the linear regime the inequality $\mathrm{m}_{\text {added }} \ll \mathrm{m}_{\text {plate }}$ must not be violated. The sensitivity was measured by depositing thin $(<10 \mathrm{~nm})$ layers of Au directly on the plate. The resonance frequencies were determined from the position of the resonance peak in the impedance spectra which were measured after each $\mathrm{Au}$ deposition. The impedance was measured with an impedance analyzer (E4990A, Keysight) actuating the CMUTs with a $50 \mathrm{mV}$ AC signal while the CMUTs are biased by an external voltage supply (2410 SourceMeter, Keithley) coupled to the CMUT through a bias-T. The pull-in voltage was found for both CMUT devices using this setup and increasing the bias

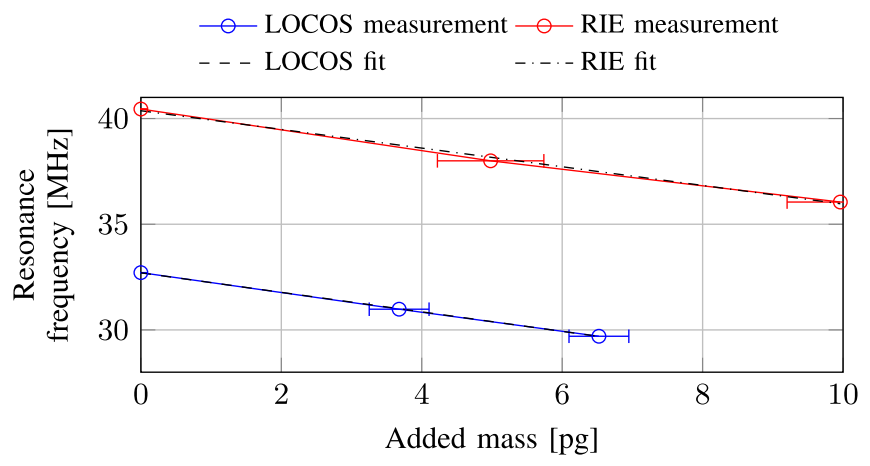

Fig. 11. Resonance frequency as a function of mass added on the plate for the LOCOS and RIE devices. The slopes of the two linear fits are the respective sensitivities. The error bars correspond to an estimated uncertainty of the $\mathrm{Au}$ thickness of $0.5 \mathrm{~nm}$ from the measurement itself and spatial nonuniformity of the sputtering process.

\section{TABLE III}

Absolute And Normalized THEORETICAL AND EXPERIMENTAL Sensitivities and Relative AdDEd Mass on the LOCOS AND RIE DEVICES. IN AdDition, $S_{\text {theo }}$ AND $S_{\text {exp }}$ ARE COMPARED ALONG WiTH SENSITIVTIES Calculated in a FEM Model

\begin{tabular}{lccc}
\hline & LOCOS & RIE & Unit \\
\hline $\mathrm{S}_{\text {theo }}$ & 0.74 & 0.84 & $\mathrm{~Hz} / \mathrm{ag}$ \\
$\mathrm{S}_{\text {exp }}$ & 0.46 & 0.44 & $\mathrm{~Hz} / \mathrm{ag}$ \\
$\mathrm{S}_{\text {theo, norm }}$ & 32.7 & 66.0 & $\frac{\mathrm{Hz} \cdot \mu \mathrm{m}^{2}}{\mathrm{ag}}$ \\
$\mathrm{S}_{\text {exp }, \text { norm }}$ & 20.3 & 34.6 & $\frac{\mathrm{Hz} \cdot \mu \mathrm{m}^{2}}{\mathrm{ag}}$ \\
$m_{\mathrm{Au}} / m_{\text {plate }}$ & 25 & 43 & $\%$ \\
$1-\mathrm{S}_{\text {exp }} / \mathrm{S}_{\text {theo }}$ & 38 & 48 & $\%$ \\
$1-\mathrm{S}_{\mathrm{FEM}, \text { loaded }} / \mathrm{S}_{\mathrm{FEM}, \text { unloaded }}$ & 28 & 48 & $\%$ \\
\hline
\end{tabular}

voltage until the resonance peak disappears, see Table II. The added mass was determined by measuring the step height of the Au layer using an AFM and calculating the mass based on the area of the plate and Au density. A plot of the resonance frequency as a function of mass added to the plate is given in Fig. 11 for both the LOCOS and RIE device. The experimental sensitivity is estimated by calculating the slope of the lines in the figure by linear regression. Table III lists the theoretical (Eq. 1) and experimental sensitivities for the two devices. For both the LOCOS and RIE device the experimental sensitivities are lower than the theoretical values which is due to the linearity assumption being broken. Table III states the fraction $m_{\mathrm{Au}} / m_{\text {plate }}$ for both devices, showing that the assumption is indeed broken. Furthermore, the flexural rigidity and mass of the added Au layer becomes non-negligible compared with that of the plate itself, which also decreases the experimental sensitivity compared with the theoretical one. The relative difference between the theoretical and experimental sensitivity is greater for the RIE device than the LOCOS device since the relative added mass is larger. The decrease in sensitivity between the mass loaded and unloaded case is studied with a simple Finite Element Method (FEM) model and the relative differences for the LOCOS and RIE devices are seen to agree. Nonetheless, both the theoretical and experimental sensitivity values, for both devices, are to the best of our knowledge the highest published for CMUTs. 


\section{CONCLUSION}

The minimization of wafer bonded CMUT cells was studied through a numerical process simulation model whose results were compared to AFM measurements of fabricated structures, giving a relative error of $\leq 5 \%$. The smallest radius one can achieve using the LOCOS cavities is by using $\mathrm{Si}_{3} \mathrm{~N}_{4}$ as the masking material which result in slope lengths that are 2 to 3 times shorter than using a $\mathrm{SiO}_{2}$ mask. Further, the pad $\mathrm{SiO}_{2}$ thickness should be decreased as well as the bump height. Lastly, it was demonstrated how the design space becomes increasingly limited for decreasing cavity dimensions.

CMUT senors were fabricated by the LOCOS and RIE processes and their mass sensitivities were both calculated and measured. The LOCOS CMUT device was designed using the findings from the simulation model while the RIE device was fabricated using $\mathrm{Si}_{3} \mathrm{~N}_{4}$ to $\mathrm{Si}_{3} \mathrm{~N}_{4}$ wafer bonding. The LOCOS and RIE devices both showed a high experimental mass sensitivity of $0.46 \mathrm{~Hz} / \mathrm{ag}$ and $0.44 \mathrm{~Hz} / \mathrm{ag}$, respectively, which for CMUTs, to our knowledge, are the highest mass sensitivities published.

\section{REFERENCES}

[1] S. Fanget et al., "Gas sensors based on gravimetric detection -A review," Sens. Actuators B, Chem., vol. 160, pp. 804-821, Dec. 2011.

[2] H. J. Lee, K. K. Park, M. Kupnik, Ö. Oralkan, and B. T. Khuri-Yakub, "Chemical vapor detection using a capacitive micromachined ultrasonic transducer," Anal. Chem., vol. 83, no. 24, pp. 9314-9320, 2011.

[3] H. J. Lee, K. K. Park, Ö. Oralkan, M. Kupnik, and B. T. Khuri-Yakub, "A multichannel oscillator for a resonant chemical sensor system," IEEE Trans. Ind. Electron., vol. 61, no. 10, pp. 5632-5640, Oct. 2014.

[4] D. Barauskas, D. Pelenis, D. Virzonis, J. P. Baltrus, and J. Baltrusaitis, "Greenhouse gas molecule $\mathrm{CO}_{2}$ detection using a capacitive micromachined ultrasound transducer,' Anal. Chem., vol. 88, no. 13, pp. 6662-6665, 2016.

[5] M. I. Haller and B. T. Khuri-Yakub, "A surface micromachined electrostatic ultrasonic air transducer," in Proc. IEEE Ultrason. Symp., Oct./Nov. 1994, pp. 1241-1244.

[6] F. L. Degertekin, R. O. Guldiken, and M. Karaman, "Annular-ring CMUT arrays for forward-looking IVUS: Transducer characterization and imaging," IEEE Trans. Ultrason., Ferroelectr., Freq. Control, vol. 53, no. 2, pp. 474-482, Feb. 2006.

[7] A. S. Savoia, G. Caliano, and M. Pappalardo, "A CMUT probe for medical ultrasonography: From microfabrication to system integration," IEEE Trans. Ultrason., Ferroelectr., Freq. Control, vol. 59, no. 6, pp. 1127-1138, Jun. 2012.

[8] B. T. Khuri-Yakub and Ö. Oralkan, "Capacitive micromachined ultrasonic transducers for medical imaging and therapy," J. Micromech. Microeng., vol. 21, no. 5, p. 054004, 2011.

[9] M. Engholm et al., "Probe development of CMUT and PZT rowcolumn-addressed 2-D arrays," Sens. Actuators A, Phys., vol. 273, pp. 121-133, Apr. 2018.

[10] K. K. Park et al., "Capacitive micromachined ultrasonic transducers for chemical detection in nitrogen," Appl. Phys. Lett., vol. 91, p. 094102, Aug. 2007.

[11] D. Virzonis et al., "Resonant gravimetric immunosensing based on capacitive micromachined ultrasound transducers," Microchimica Acta, vol. 181, pp. 1749-1757, Oct. 2014.

[12] Y. Huang, A. S. Ergun, E. Haeggström, M. H. Badi, and B. T. Khuri-Yakub, "Fabricating capacitive micromachined ultrasonic transducers with wafer-bonding technology," J. Microelectromech. Syst., vol. 12, no. 2, pp. 128-137, Apr. 2003.

[13] K. K. Park, H. Lee, M. Kupnik, and B. T. Khuri-Yakub, "Fabrication of capacitive micromachined ultrasonic transducers via local oxidation and direct wafer bonding," J. Microelectromech. Syst., vol. 20, no. 1, pp. 95-103, Feb. 2011.

[14] D. Chin, S.-Y. Oh, S.-M. Hu, R. W. Dutton, and J. L. Moll, "Twodimensional oxidation," IEEE Trans. Electron Devices, vol. ED-30, no. 7, pp. 744-749, Jul. 1983.
[15] T.-C. Wu, W. T. Stacy, and K. N. Ritz, "The influence of the LOCOS processing parameters on the shape of the bird's Beak structure," J. Electrochem. Soc., vol. 130, no. 7, pp. 1563-1566, 1983.

[16] N. Guillemot, G. Pananakakis, and P. Chenevier, "A new analytical model of the "Bird's beak," IEEE Trans. Electron Devices, vol. ED-34, no. 5, pp. 1033-1038, May 1987.

[17] A. F. Sarioglu, M. Kupnik, S. Vaithilingam, and B. T. Khuri-Yakub, "Nanoscale topography of thermally-grown oxide films at right-angled convex corners of silicon," J. Electrochem. Soc., vol. 159, no. 2, pp. H79-H84, 2011.

[18] T. L. Christiansen, O. Hansen, J. A. Jensen, and E. V. Thomsen, "Thermal oxidation of structured silicon dioxide," ECS J. Solid State Sci. Technol., vol. 3, no. 5, pp. N63-N68, 2014.

[19] Q. Stedman, K. K. Park, and B. T. Khuri-Yakub, "CMUT chip with integrated temperature and pressure sensors," in Proc. IEEE Int. Ultrason. Symp., Sep. 2016, pp. 1-4.

[20] K. Reck, C. Østergaard, E. V. Thomsen, and O. Hansen, "Fusion bonding of silicon nitride surfaces," J. Micromech. Microeng., vol. 21, p. 125015, Nov. 2011.

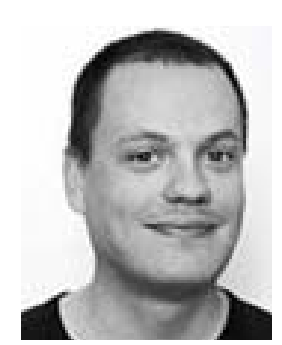

Mathias J. G. Mølgaard received the B.Sc. and M.Sc. degrees in engineering physics and nanotechnology from the Technical University of Denmark, Kongens Lyngby, Denmark, in 2012 and 2015, respectively, where he is currently pursuing the Ph.D. degree with the MEMS Applied Sensors Group, focusing on gravimetric sensing using capacitive micromachined ultrasonic transducers.

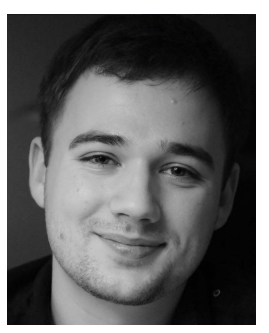

Jesper M. F. Hansen received the B.Sc. and M.Sc. degrees in engineering physics and nanotechnology from the Technical University of Denmark, Kongens Lyngby, Denmark, in 2015 and 2017, respectively. $\mathrm{He}$ is currently a Production Engineer with the company NIL Technology, Kongens Lyngby.

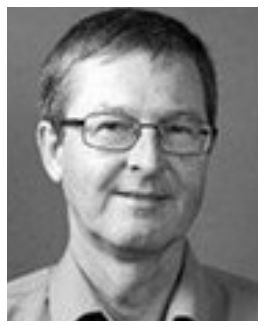

Mogens H. Jakobsen received the M.Sc. and Ph.D. degrees in chemistry from the University of Copenhagen, Denmark, in 1987 and 1990, respectively. In 1995, he left his job as an Assistant Professor at the University of Copenhagen to become CSO \& VP R\&D as the co-founder of Exiqon A/S, Denmark. In 2003, he left Exiqon A/S for a position as an Associate Professor at DTU Physics followed by a position as a Senior Researcher at Cantion A/S, Denmark. In 2006, he joined DTU Nanotech, Technical University of Denmark, where he is currently an Associate Professor. He is also the Group Leader of the Surface Engineering Group, Technical University of Denmark.

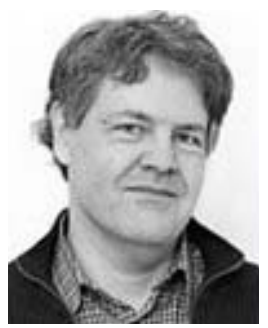

Erik V. Thomsen was born in Aarhus, Denmark, in 1964. He received the M.Sc. degree in physics from Odense University, Odense, Denmark, and the Ph.D. degree in electrical engineering from the Technical University of Denmark, Kongens Lyngby, in 1998. He is currently a Professor at DTU Nanotech, Technical University of Denmark, where he is also the Head of the MEMS Applied Sensors Group. His current research and teaching interests include MEMS multisensors, bio-medicaldevices, small scale energy systems such as miniature fuel cells and energy harvesting devices, capacitive micromachined ultrasonic transducers, and piezoelectric MEMS. He teaches classes in solid state electronics, microtechnology, and nano- and micro-fabrication. He received the AEG Electron Prize in 1995 and has also received several teaching awards at DTU. 